\title{
Emociones y subjetividad. \\ Un análisis desde abajo de las luchas por la defensa del territorio
}

\section{Alice Poma}

Grupo de investigación: Actores sociales, representaciones y prácticas políticas (EEHA, CSIC) alicepoma@gmail.com

\section{Resumen}

El objetivo del artículo es presentar una lectura de las luchas por la defensa del territorio desde la perspectiva de los afectados, mostrando los resultados de investigación basados en tres estudios de caso de resistencias contra presas.

Rechazando la etiqueta NIMBY, en este trabajo, proponemos un análisis desde abajo, es decir, desde la vivencia de las personas de las comunidades afectadas que lucharon para defender sus territorios, y dedicaremos especial atención a la dimensión emocional de estas experiencias y sus consecuencias.

Entre otras técnicas de recolección de datos y análisis, nuestro diseño de investigación incluye entrevistas en profundidad a los afectados que participaron en las luchas, aunque se ha decidido no entrevistar a activistas de organizaciones ecologistas y/o políticas.

Con este trabajo, nos sumamos a las voces que han contribuido a invalidar las perspectivas que consideran que los ciudadanos que defienden el territorio son ignorantes, egoístas e irracionales. Por el contrario, queremos mostrar que las emociones desempeñan un papel importante en estas resistencias, lo cual no sólo influye en la motivación, sino también en los resultados de la protesta, como el empoderamiento.

Palabras clave: resistencias de base; choque moral; sentimiento de injusticia; apego al lugar; empoderamiento.

Abstract. Emotions and subjectivity: An analysis from below of the struggles for the defence of the territory

The aim of this paper is to provide insight into struggles to defend the territory from the viewpoint of those involved. The study is based on the results of three case studies on opposition to dams. We reject the NIMBY label approach, and instead propose an analysis from below, that is, from the experience of the affected communities who strive to defend their territories. Special attention is given to the emotional dimension of these experiences 
and their consequences. Among other data collection and analysis techniques, our research design includes in-depth interviews of the individuals who have participated in these struggles, with the exception of external ecological and political activists. This paper aims to join the voices that have contributed to invalidating perspectives which consider citizens who defend the territory as ignorant, selfish and irrational by showing that emotions play an important role in these resistance movements in that they not only influence motivation, but also the outcomes of the protest, such as empowerment.

Keywords: grassroots resistance; moral shock; injustice frame; place attachment; empowerment.

\section{Sumario}

Introducción Las emociones como detonante

Metodología

Un acercamiento al estudio de las luchas por la defensa del territorio

Las emociones como factores explicativos de la resistencia

Las emociones como motor de cambio: energía emocional y empoderamiento

Conclusiones

Referencias bibliográficas

\section{Introducción}

Resistir contra la construcción de una presa que inundará tu casa, tus recuerdos, tus muertos, tu tierra, el trabajo de toda una vida y tus sueños es una experiencia intensamente emocional, debido tanto a los impactos de estas obras en la vida de los habitantes de los territorios afectados, cuanto a la propia experiencia de oposición. Como expresó un hombre que luchó contra la desaparición de su pueblo bajo las aguas de un embalse en España:

[...] era una mezcla de impotencia y de mucha rabia, impotencia y rabia, rabia y afán de luchar contra algo tan injusto y para mí tan inconcebible. (E.Ri.1)

El propósito de este trabajo es contribuir a la comprensión de las luchas por la defensa del territorio desde la vivencia de los que lucharon, ya que, como evidencian las autoras italianas Fedi y Mannarani (2008: 11): «[...] raramente ha sido analizado el significado simbólico y emotivo que la defensa del propio territorio asume». Basándonos en el análisis de tres resistencias contra la construcción de presas en España y en México, pondremos en resalto el fuerte impacto emotivo que caracteriza estas experiencias para comprender las razones que mueven a las personas a defender su territorio, así como el cambio que estas viven durante la práctica de lucha.

Los límites de la literatura existente sobre conflictos ambientales reside en el hecho de que, como afirmó Krauss (1993: 248), las actividades de protesta de la gente común «han sido a menudo trivializadas, ignoradas y vistas como acciones interesadas, particularistas y parroquianas». La literatura sobre conflictos ambientales se ha centrado en el carácter egoísta y no universal de estas experiencias, que han sido definidas como NIMBY ('no en mi patio trasero'), 
interpretación que considera estas luchas como problemas y «generadoras de crisis» (Uribe-Salazar Gil y Pascual Martí, 2013), lo cual ha generado una amplia literatura enfocada en la resolución y el manejo de estos conflictos, más centrada en desarrollar mecanismos de captación e infiltración en las comunidades locales para "desactivar los efectos de un NIMBY» (ídem: 10), que en la comprensión de estas experiencias. En nuestra investigación, proponemos mostrar la invalidez de dichas interpretaciones, mostrando como estas luchas por la defensa del territorio pueden causar otros resultados, visibles si son analizadas desde abajo.

El enfoque desde abajo que caracteriza a nuestra investigación incorpora al análisis la dimensión cotidiana de la lucha que se aborda a través de la experiencia de los sujetos, de sus biografías y de sus emociones. El potencial del enfoque desde abajo, que nos hace invertir la mirada hacia los sujetos normalmente ignorados por el poder y por la academia, reside en su capacidad de revalorizar la cotidianeidad para comprender el cambio social.

Pasamos ahora a describir las herramientas metodológicas empleadas en la investigación empírica, para luego presentar algunas aportaciones teóricas que contribuyeron a diseñar nuestra investigación y, sucesivamente, presentar el análisis de la dimensión emocional de los conflictos.

\section{Metodología}

Las herramientas metodológicas empleadas en la investigación han sido el estudio comparado de casos y el análisis cualitativo de la información recogida a través de entrevistas semiestructuradas, principalmente individuales, no directivas ${ }^{1}$, guiadas y en profundidad a los participantes de los conflictos, miembros de las comunidades afectadas. Decidimos, además, utilizar lo que Flick (2000 y 2004) denomina entrevista episódica, en la que se pide a la persona entrevistada que cuente episodios de su experiencia. En nuestra investigación, se ha demostrado una herramienta útil, porque «facilita la presentación de las experiencias en una forma general, comparativa, $y$, al mismo tiempo, asegura que esas situaciones y episodios se cuentan en su especificidad» (2004: 119). A través de la narración de los acontecimientos, «descubrimos algunos hechos considerados muy relevantes, no sólo porque aparecen en muchos de los relatos, sino también por la enorme emotividad que generan» (Sanz Hernández, 2000: 54) y exploramos valores, ya que, como escribe Atkinson (2002: 92): «los acontecimientos son empapados y guiados por valores». La selección de los entrevistados la hicimos tanto a través de los informantes clave, como pidiendo a los entrevistados otros contactos (muestreo «bola de nieve»). En total, la investigación se basa en un total de sesenta entrevistas, incluidas unas

1. Se definen como no directivas las entrevistas que no prevén un abanico de respuestas cerradas, es decir, son preguntas abiertas. «La naturaleza no directiva se justifica en base al principio de centralidad del entrevistado: ya que el objetivo cognitivo concierne a la realidad que él vive en primera persona y, desde el momento que él es el verdadero experto de esa realidad, es él quien conduce la entrevista» (Diana y Montesperelli, 2005: 17). 
pocas que fueron informales y no grabadas, de las que sólo una mínima parte será citada en el análisis².

La decisión de elegir como sujetos de nuestra investigación a personas de las comunidades afectadas que lucharon contra el proyecto, en lugar de entrevistar a activistas o a líderes de organizaciones implicadas, se sostiene en la idea de que «la entrevista a los militantes de base [o personas comunes] ${ }^{3}$ será más útil para reconstruir los procesos difusos de construcción social del mundo circundante, o la manera en la que las ideologías abstractas se traducen en prácticas concretas» (Della Porta, 2010: 69). Además, como escribe Holloway (2011: 13): «el cambio social no es producido por los activistas [...] es mas bien el resultado de la transformación apenas visible de las actividades cotidianas de millones de personas». El enfoque desde abajo y el hecho de centrarse en la experiencia de la lucha, en su dimensión subjetiva y emocional, presupone una elección metodológica que está íntimamente relacionada con la utilización exclusiva de técnicas de investigación cualitativas, "pero siempre y cuando a través de ellos se exprese la voz, incluso la mirada, el sentir, la subjetividad de los sujetos de la investigación» (Regalado, 2012: 172).

Pasando ahora a la selección de los casos, se trata de dos ejemplos victoriosos y uno de fracaso, dos de ellos son españoles y uno mexicano. La lucha por la defensa de río Grande en Málaga es un acontecimiento contemporáneo en el que la población de la comarca de Coín consiguió parar la construcción de un azud que implicaba un trasvase del agua del río hacia Málaga. El conflicto vio la participación masiva de la población y la desestimación del proyecto anunciada en 2007. La lucha por la defensa de río Grande en la comarca de Coín es un ejemplo paradigmático de una lucha local, en la que, gracias al trabajo de actores locales que se empeñan en el territorio desde décadas, fue involucrándose toda la comunidad. Aunque la afectación de este conflicto era mucho menor que la de los demás casos, su discurso y su práctica, centrados en la cultura, así como la participación de la mayoría de la población del pueblo en el conflicto, fueron las razones que nos llevaron a seleccionarlo para nuestra investigación.

La lucha contra el embalse de Riaño fue elegida por ser un caso emblemático en España. Este ejemplo representa el sufrimiento y el dolor proporcionado por una política autoritaria que, en nombre del progreso y del interés general, ha condenado ocho pueblos a desaparecer. La resistencia contra el embalse de Riaño puede ser considerada la última de la dictadura o la primera de la democracia. Es más, podemos decir que Riaño es una metáfora de la naturaleza de la democracia española: la presa construida durante la dictadura, bajo la cual también empezaron las expropiaciones, fue cerrada por el primer gobierno democrático socialista, contrariamente a las promesas electorales hechas en la comarca. A nuestro entender, la violencia con la que se desalojaron y

2. Al final del artículo, el lector encontrará una tabla con las entrevistas citadas de los tres casos de estudio.

3. Della Porta (2010: 69) distingue entre entrevistas a las elites y entrevistas a las personas comunes, como estrategias diferentes de investigación. 
se derrumbaron las viviendas de los habitantes que decidieron resistir en los pueblos luego inundados representa una línea de continuidad con el pasado. Hemos creído que, tanto por su carga emocional como por su simbolismo democrático, el caso de Riaño era el más interesante para ser incorporado al análisis.

El tercer acontecimiento que presentamos es el mexicano. Consideramos que salir de Europa, es decir, de un contexto socioeconómico-cultural determinado, nos permitía poder verificar nuestras ideas con mayor fuerza. Todo el continente americano, desde México hasta Patagonia, en las últimas décadas, está siendo objeto de la implementación de modelos extractivistas (AA.VV., 2009) que, entre muchas consecuencias, fomentan la proliferación de proyectos ${ }^{4}$ que provocan graves resultados ambientales y sociales (Delgado Ramos, 2013). Estos proyectos son el reflejo de una política de dominación que permite conseguir recursos naturales a bajo coste económico, pero a altísimo coste humano, social y ambiental. Decidimos, así, incorporar un caso mexicano que fuese victorioso y contemporáneo, semejante o con características parecidas al caso de Coín, para facilitar la comparación entre los dos, y la lucha contra la presa de San Nicolás en Jalisco se ajustaba a estos requisitos. Es una circunstancia poco anterior a la de Coín y que, como esta última, también duró, en su fase más visible, unos nueve meses. Además, nos llamó la atención por ser un caso muy poco estudiado, como Riaño, y, como este último, con un fuerte impacto sobre el territorio, ya que se inundaban dos pueblos y varios ranchos ${ }^{5}$, lo cual afectó a miles de personas ${ }^{6}$. Ese último aspecto se ha convertido en clave de una de las respuestas, ya que nos permitía comparar ejemplos de fuerte impacto material con el de Coín, en el que el impacto era mucho menor, para comprobar las razones de la protesta, verificar que el egoísmo no desempeñaba un papel importante en las acciones realizadas y que, como veremos a continuación, el apego al territorio era un elemento clave para entender estas oposiciones.

Antes de presentar nuestro análisis de la dimensión emocional de la protesta, en el siguiente apartado, haremos un breve excurso de la literatura sobre conflictos ambientales y resistencia que nos ayudó en el diseño de nuestra investigación.

\section{Un acercamiento al estudio de las luchas por la defensa del territorio}

De manera un tanto inusual en el contexto de un trabajo de investigación, el primer acercamiento a la comprensión subjetiva de las experiencias por la

4. No pensamos sólo en proyectos hidráulicos, que son muchos, sino también en la minería, en las extracciones petroleras, en vías de comunicación y hasta en proyectos que implementan energías sostenibles, como la eólica.

5. Finca rural, pequeña y humilde, y casco de la misma. Fuente: «Diccionario del español usual en México». Biblioteca Virtual Miguel de Cervantes. www.cervantesvirtual.com.

6. De acuerdo con las cifras del INEGI (Instituto Nacional de Estadística y Geografía de México), el número de afectados era de tres mil doscientas personas, mientras que, según el comité pro San Gaspar, que consideraba los flujos migratorios, llegaba a los diez mil. 
defensa del territorio fue a través de historias narradas en libros y en material autoproducido por colectivos españoles y mexicanos, entre los que incluimos abundante documentación audiovisual. Estas fuentes resultaron útiles como fuente de inspiración durante el desarrollo del diseño de la investigación, ya que nos permitió acceder a historias de personas y de comunidades afectadas por obras hidráulicas antes de empezar el trabajo de campo. Estudiando este material, nos dimos cuenta rápidamente que, para comprender estas experiencias en profundidad, era necesario incorporar en nuestro análisis su dimensión emocional, incluida la relación entre los seres humanos y su territorio.

Acudimos, así, a la literatura sobre el estudio de las emociones en la protesta, ya que la información sobre conflictos ambientales resulta ser muy sesgada, y etiquetamos a las oposiciones locales como NIMBY (Not in My Back Yard) ${ }^{7}$. Esta visión se basa en la idea de que los que se oponen a las instalaciones ignoran los beneficios de las mismas y responden a motivaciones egoístas e irracionales. Los autores que critican esta interpretación demuestran que el NIMBY responde a una lógica que "privilegia la pericia centralizada a expensas de las voces de la comunidad local» (Gibson, 2005: 383) y no refleja la realidad de estas experiencias, que, como veremos, se caracterizan por una carga emocional muy fuerte, que tiene muy poco que ver con comportamientos egoístas y conservadores. Por esta razón y por ser NIMBY un término usado en las disputas locales sobre el desarrollo para desacreditar a los opositores, muchos autores invitan a abandonar el uso de esta etiqueta. Entre ellos, destacamos a Gibson (2005: 383), que afirma:

[...] ha llegado el momento para los sociólogos críticos y los defensores [de estas experiencias] de abandonar el punto de vista convencional sobre los movimientos de oposición local. En primer lugar como marco analítico, ya que la noción misma de síndrome NIMBY engloba dicotomías simples e insostenibles que no sirven para analizar las complejidades sociales y espaciales de los conflictos sobre el uso del territorio.

Wolsink (2006: 90) también ha atacado esa perspectiva de manera contundente, afirmando que «la aplicación del argumento NIMBY como herramienta para el análisis es científicamente peligrosa y debe ser abandonada».

Entre los autores que propusieron acercamientos alternativos a la actuación NIMBY, nos parecieron valiosas las aportaciones de Vorkinn y Riese (2001), Devine-Wright (2009 y 2011), que, entre otras cosas, propone repensar estas experiencias como «acciones de protección del lugar, basadas en procesos de apego al lugar e identidad» (2009: 426). Una obra que también nos guió en el diseño de nuestra investigación desde una perspectiva crítica a la actuación NIMBY ha sido la de Fedi y Mannarini (2008). Las autoras ofrecen elementos para el análisis de estas experiencias desde la perspectiva de la psicología social,

7. La etiqueta NIMBY ('no en mi patio trasero') se emplea como una acepción despectiva para referirse a los movimientos de protesta de base local o a los activistas individuales que se oponen a una instalación. 
haciendo hincapié, por ejemplo, en la importancia del sentimiento de injusticia colectiva percibido por las poblaciones afectadas por una infraestructura. $\mathrm{Su}$ propuesta de análisis incluye también el estudio del cambio social que promueven estas experiencias de resistencia, la identidad pospolítica de sujetos que rechazan la política institucional, la contraidentidad que se elabora durante estas experiencias, caracterizada por un estatus de superioridad atribuido a lo que está abajo, así como los valores autónomos de los movimientos, entre los que destacan la defensa del territorio, la autoorganización como necesidad y la singularidad frente a la uniformidad. Otra aportación que ha influido en el diseño de nuestro análisis es la concepción de eventful protest, en la que Della Porta (2008) propone focalizarse en las dinámicas internas y en la capacidad transformadora de la protesta. La idea de la autora es que las protestas tienen muchos efectos cognitivos, afectivos y relacionales sobre los mismos movimientos. Esta contribución se enfoca en la capacidad transformadora de la protesta que se convierte en un laboratorio cultural que, independientemente de los resultados más obvios, influye en el cambio social.

Estas aportaciones, entre otras que no nos da tiempo citar, fueron determinantes en el diseño de nuestra investigación y en el análisis de los casos de estudio que presentaremos a continuación, y que está enfocado en la dimensión emocional de estas experiencias. Pero, además, considerando las luchas por la defensa del territorio experiencias de resistencias en las que personas "comunes y corrientes» se enfrentas a gobiernos y promotores, no podíamos dejar de referirnos a James Scott (2000). El autor analiza las formas cotidianas de resistencia, en las que se evidencia la relación entre la ruptura de la rutina y la movilización, idea que encontramos también en Jasper (1997: 124), cuando afirma que la resistencia «no deriva sólo del posible riesgo percibido, sino también del apego al lugar y a las rutinas que se resumen en el concepto de hogar».

En nuestro ámbito de estudio, cuando nos referimos a la resistencia, pensamos principalmente en su dimensión cotidiana, que puede ser invisible, sutil ${ }^{8}$ y, sobre todo, constituir el «terreno de la infrapolítica» (Scott, 2000: 233), es decir, de la política de los grupos subordinados. La infrapolítica es la "gran variedad de formas de resistencia discretas» (Scott, 2000: 44), que «se caracteriza por liderazgo informal, de las no elites, de la conversación y del discurso oral» (Scott, 2000: 236). Ese concepto es indispensable para entender los eventos aparentemente ocasionales de protesta o insurrección, porque explica la existencia de un «discurso oculto» de los subordinados, que, en eventos especiales, emerge y se hace público. Ese discurso oculto «representa una crítica al poder a espaldas del dominador» (Scott, 2000: 21), es un producto social «resultado de las relaciones de poder entre subordinados», emerge en los espacios sociales y marginales y cuando hay más gente que lo comparte, y «existe sólo en la medida en que es practicado, articulado, manifestado y diseminado dentro de los espacios sociales marginales» (Scott, 2000: 149). Y allí está su trascendencia, en

8. Scott diferencia entre las formas de resistencia abiertas, declaradas, y la resistencia «travestida", de bajo perfil (Scott, 2000: 233). 
experiencias como las luchas por la defensa del territorio, porque, si es verdad que los movimientos formales y organizados pueden dotar de argumentos a los afectados, el discurso oculto es el substrato que alimenta la resistencia.

Además de la existencia de la infrapolítica, para entender estas experiencias, no podemos olvidar la relación entre dominio y resistencia, ya que, donde hay dominio, hay resistencia a la dominación y, donde surgen nuevas formas de dominación, acaban apareciendo nuevas formas de resistencia (Scott, 2000; Holloway et al., 2009). Scott (2000: 71) escribe que «las relaciones de poder son también relaciones de resistencia» $\mathrm{y}$, en nuestros casos, el poder se ejerce desde el centro, normalmente desde el estado, hacia la periferia. Las periferias, olvidadas durante siglos, como afirma Scott: «ahora resulta que tienen mucho valor, porque disponen de recursos, por eso se ha ido hacia el control de la periferia de manera masiva ${ }^{9}$. Y en este cuadro se enmarcan nuestros casos de estudio, que son lugares periféricos respecto a los centros de poder político y económico, que pueden ser sacrificados por lo que el estado considera «interés general» para proporcionar recursos al sistema productivo del país, y cuya población, habitualmente pequeña en número, tendría que aceptar su destino, cosa que, por suerte, muchas veces no pasa. Ello facilita que territorios y culturas sigan existiendo.

Como hemos escrito al principio del artículo, creemos que estas resistencias no se pueden comprender en profundidad sin analizarlas desde abajo, desde la experiencia de los sujetos e incorporando las emociones, ya que, como veremos a continuación, las emociones producen «levantamientos geológicos del pensamiento» ${ }^{10}$, que no sólo motivan a las personas a resistir, sino que además determinan hasta dónde pueden llegar y cambian su visión del mundo, ya que, como escribió Aristóteles: «las emociones son aquellas cosas que hacen que, al experimentar un cambio, las personas acaben por diferir en sus juicios» ${ }^{11}$.

\section{Las emociones como factores explicativos}

Revisando la literatura existente sobre las emociones en la protesta ${ }^{12}$, confirmamos nuestras intuiciones sobre la trascendencia del estudio de las emociones que permiten tanto explicar por qué las personas de las comunidades afectadas se movilizan, cuando cómo estas personas han «despertado» ${ }^{13}$ y reelaborado sus ideas sobre el mundo, que luego se traducen en nuevas prácticas. Como evidenció Jasper (2012), las emociones son un factor explicativo útil para comprender la interacción social desde el punto de vista de las figuras más destaca-

9. En la conferencia magistral «Sobre el arte de no ser gobernados» en la UNAM, México, el 10 de enero de 2012 y cuya transmisión en vivo estuvo disponible en la red (www.celich. unam.mx/0/70TraViv.php).

10. Marcel Proust, A la busca del tiempo perdido, Madrid: Valdemar, 2002.

11. Aristóteles, La Retorica, Milano: Mondandori, 1996.

12. Entre los autores de referencia, destacan: Donatella Della Porta, Helena Flam, Jeff Goodwin, Deborah Gould, James M. Jasper y Francesca Polletta.

13. Así como los expresan los protagonistas de las luchas. 
das de estas experiencias de protesta, porque las emociones ayudan a explicar el origen y el alcance de los movimientos sociales, así como su continuación o declive (Jasper, 1998). Las emociones son «un elemento fundamental de la sociedad» (Flam y King, 2005: 3) y ejercen efectos significativos en los movimientos (Gould, 2004). De hecho, las consecuencias relacionales, cognitivas y emocionales de la protesta afectan a los propios movimientos (Della Porta, 2008; Jasper, 1997) y se relacionan con la capacidad de transformar la protesta. Partiendo de estas premisas y asumiendo la importancia de las emociones en la protesta ${ }^{14}$, ¿de qué manera el estudio de las emociones puede contribuir a una mejor comprensión de las luchas por la defensa del territorio? Y, además, ¿qué emociones analizamos y cómo?

En el marco de nuestra investigación, las emociones permiten comprender por qué la gente defiende su territorio, así como su determinación en la lucha, pero, además, permiten comprender cómo la lucha puede fortalecer y empoderar a los individuos, por ejemplo, creando y fortaleciendo los vínculos entre las personas o con el territorio. Una característica propia de estas experiencias es que la relación con el territorio que se defiende tiene una dimensión emocional y simbólica muy importante, tanto que, como veremos a continuación, una de las motivaciones para defender una tierra, un pueblo, un río, etc. es el vínculo emocional y sentimental que relaciona el lugar y su gente. Las emociones influyen, también, en la construcción de la amenaza, en la identificación de los culpables y, como consecuencia, en la construcción de la identidad antagónica entre «nosotros» $\mathrm{y}$ «ellos». Pero, además, aunque no haya relación emocional directa, el sentimiento de injusticia, la indignación o el ultraje llevan a muchas personas a involucrarse en una lucha. Siendo, además, conflictos locales, las emociones y los vínculos entre las personas resultan tener un papel en la dinámica del conflicto, tanto animando como desanimando a la participación. Integrar el rol de las emociones al estudio de estas experiencias locales de protesta contribuye a comprender las respuestas de la gente, el aprendizaje consecuente a la experiencia del conflicto, los procesos que llevan a la toma de conciencia y a la trasformación de los participantes en sujetos políticos que reivindican derechos más allá de la motivación que los llevó a tomar parte en el conflicto. Finalmente, la incorporación de las emociones en el estudio de las luchas por la defensa del territorio permite superar, además, la acusación de irracionalidad, ya que se acepta la idea de que «la racionalidad está echa por emociones» (Jasper, 1998: 398).

Para concluir, hay que determinar qué emociones analizaremos y cómo, ya que incorporarlas al análisis presupone confrontarse con dificultades analíticas, ya que «los sentimientos son la componente menos estudiada, por ser la más difícil de abordar» (Hidalgo, 1998: 53). Puesto que es imposible abarcar en este artículo cada aspecto analizado en nuestra investigación, hemos decidido dividir el análisis en dos apartados. En el primero, nos focalizaremos en tres aspectos que consideramos centrales a la hora de entender por qué la gente

14. Para profundizar más en este aspecto, véase Poma (2013), Poma y Gravante (2013). 
defiende su territorio: el choque moral ${ }^{15}$, el sentimiento de injusticia y el apego al lugar; a continuación, concluiremos mostrando el empoderamiento de los sujetos como resultado de estas experiencias, así como el papel de las emociones en este proceso.

\section{Las emociones como detonante de la resistencia}

El análisis que presentaremos en las próximas páginas consiste en mostrar cómo el impacto emocional que acompaña a la construcción de una presa es uno de los detonadores de la resistencia. A través del análisis de algunos de los procesos cognitivos como el choque moral y el sentimiento de injusticia, observados en los casos concretos, y el análisis del apego al lugar, mostraremos lo que mueve a la gente a organizarse y resistir, más allá de intereses materiales, costes y beneficios. Empezaremos describiendo el choque moral producida por la noticia de la construcción de la obra hidráulica, para luego analizar el proceso que permite que las personas determinen que lo que están viviendo es una injusticia y cómo influye el vínculo con el territorio en la decisión de resistir. Para facilitar la lectura, hemos optado por citar sólo unos pocos extractos de entrevistas por cada elemento presentado.

\section{El choque moral}

La noticia de que se va a construir una infraestructura que puede cambiar para siempre el territorio en el que una persona vive, trabaja o veranea, y con el que se ha construido un vínculo afectivo, produce una respuesta emocional que contribuye a poner en discusión creencias y valores. El procesamiento cognitivo que sigue a la respuesta emocional es lo que Jasper define como choque moral, es decir, «la vertiginosa sensación que se produce cuando un evento o información muestra que el mundo no es como uno lo pensaba, y que puede a veces llevar a una articulación o reelaboración de principios morales» (Jasper, 2011: 289). En otras palabras, el choque moral, por la carga emocional que producen determinados eventos (o informaciones) relacionados con cambios en el territorio, puede provocar una reelaboración de la realidad y de los valores de una persona. Este proceso presupone un momento de ruptura en la cotidianeidad de los actores, que tendrán que reaccionar a los cambios y a las amenazas percibidos, elementos que los inducirán a la acción. En nuestros casos analizados, el primer choque se produce con la noticia de la construcción de la presa, que en ninguna de las tres ocasiones fue anunciada públicamente, sino descubierta a través de periódicos locales, «rumores» (E.Sg.6) o, como en el ejemplo de Coín, por la llegada de las primeras cartas de expropiación. Así es como describió ese momento una mujer mexicana:

15. En inglés, moral shock, es un concepto propuesto por Jasper (1998 y 2011) e indica la respuesta emocional a un evento o información que influye en la motivación para la acción. 
[...] llega el momento que tanto oyes, y preguntas [acerca del proyecto] Ya es cuando te empieza a entrar la duda y el miedo, y ya te unes a la gente, sin querer, o sea, cuando menos acuerdas ya andas bien involucrado en todo. (E.Sg.9)

Las emociones que caracterizan ese momento, como el miedo por las consecuencias que puede aportar el proyecto, son alimentadas por el discurso oculto presente en la sociedad (Scott, 2000) y la experiencia y la vivencia de otras personas. De esta manera, por ejemplo, el estado se convierte en enemigo, no sólo actual, sino también histórico, como podemos observar en Riaño y en San Gaspar, donde surge la recuperación de episodios del pasado que evidencian la conflictividad entre los habitantes del territorio y el poder dominante:

[...] esta región siempre es lo que desde tiempo atrás es la lucha por la tierra, por tu estancia, por tu cultura, por tu forma de vida, pues yo pienso que si ya nuestros abuelos, nuestros antepasados, tuvieron que partirse la madre por estar aquí, yo creo que si a nosotros nos tocó vivir en este tiempo, pues algo tenemos que hacer. (E.Sg.6)

$\mathrm{El}$ «discurso oculto» se puede encontrar en la relectura de eventos del pasado percibidos como una injusticia por los habitantes del territorio o en el discurso que alimenta la división entre el territorio afectado y el beneficiario que goza de más privilegios. En el caso de Coín, el enfrentamiento es entre la ciudad de Málaga y su costa, consagradas al turismo de sol y playa, y las comarcas circundantes que ofrecen recursos, tanto humanos, es decir mano de obra, como naturales, mientras en el caso de Riaño es el enfrentamiento entre la montaña, aparentemente improductiva, y la llanura, con su producción agrícola:

Aquí enfrentaron a la tierra de campos con la montaña [...] había que sacrificar esta zona para que otra zona [...] yo no lo entendía que tuvieran que sacrificar nuestra tierra para que otra gente progresara. (E.Ri.3)

De esta manera, el choque moral influye también en la elaboración de la dicotomía entre "nosotros» $\mathrm{y}$ «ellos», o «los de abajo» $\mathrm{y}$ «los de arriba», es decir, entre el gobierno que ejerce el poder y las personas, y la consecuente toma de conciencia de la falta de derechos reales de los ciudadanos, como se puede apreciar en este extracto:

[...] aquí luchábamos por algo, sin violencia, además que en un ambiente festivo [...] la Subdelegación del Gobierno nos prohibió el derecho a manifestarnos [...] Eso yo creo que fue un impulso más, la gente se rebeló aún más. (E.Co.2)

En este caso, el choque moral es la consecuencia de la prohibición a manifestarse, así como en San Gaspar y Coín fue a causa de la represión y el hostigamiento que sufren los afectados durante la lucha. En estos momentos, los ciudadanos se dan cuenta de que no tienen derecho ni a manifestarse, 
sentimiento que radicaliza la lucha, ya que lo que entra en juego es el derecho y la libertad de expresión, además de poder decidir sobre su propio territorio. Las emociones, como la indignación, que acompañan a ese choque cambian las prioridades de las personas involucradas, que empiezan a unirse, organizarse y elaborar sus razones de forma individual y colectiva, hasta que llega el momento en el que deciden modificar su cotidianeidad para volcarse en la resistencia:

[...] entonces llegó un momento que ya perdí lo que hubiera que perder para poder colaborar con ellos [los amigos implicados en la lucha] en lo que fuera... La protesta, lo de todos, luchar por salvar Riaño. (E.Ri.2)

El choque moral es central para comprender estas experiencias, porque es el momento en el que empieza el proceso de cambio cultural, considerado como el proceso que lleva a comprender que «el mundo no es como lo pensabas» (Jasper, 1998: 409) y que clarifica y activa los valores subyacentes de la gente (Jasper, 2011: 293). En los casos de estudio analizados, por ejemplo, el choque moral ante la posible pérdida del río produjo un proceso de revalorización del medio y de sus elementos:

[El río] es algo tan cotidiano, nuestro, que no le estábamos dando la importancia que realmente tenía, y cuando realmente te dicen que va a dejar de existir..., allí es cuando dices tú..., que no, que no quiero que deje de que exista, a lo mejor no le he dado la importancia que tenía, pero cuando peligra, si que le das la importancia. (E.Co.5)

Uno de los resultados de nuestra investigación fue comprobar que, a través de procesos cognitivos producidos y alimentados por emociones, los protagonistas de nuestros casos de estudio han empezado un proceso de elaboración que les está llevando a poner en discusión sus ideas sobre el gobierno, los medios de comunicación, el progreso y la democracia ${ }^{16}$. La amenaza principal que ellos sienten es la pérdida del pueblo y/o del río y de todo lo que comprenden en cuanto a vínculos, redes, estilo de vida, recuerdos, patrimonio, etc. La identificación de los culpables permite dirigir la propia rabia y el propio dolor hacia el Gobierno. Pero existe otro proceso cognitivo que puede potenciar el conflicto, y es el percibir lo que se está viviendo como una injusticia o, como lo definió Gamson (1992), el injustice frame. Percibir lo que se está viviendo como una injusticia justifica el conflicto, independientemente de los argumentos a favor o en contra de una instalación. El sentimiento de injusticia, que se construye individual y colectivamente, hermana y une a los que lo comparten, y fortalece los vínculos de solidaridad. Pero veamos ahora cuáles son los elementos que permiten enmarcar la experiencia concreta como una injusticia. 


\section{El sentimiento de injusticia}

En las experiencias analizadas, la construcción de la presa es algo percibido como injusto. La injusticia está relacionada con la magnitud de la afectación y con la idea de que los promotores tienen intereses particulares en el proyecto. Como podemos leer en este testimonio, los afectados se indignan frente a la magnitud de su perjuicio, que, sumado a la falta de razones, parece aún más desproporcionado. Como afirmó una mujer que resistió en Riaño: «me parecía que era una masacre lo que iban a hacer» (E.Ri.5), y esto crea indignación, como se puede apreciar en el testimonio de un agricultor andaluz:

[...] y cuando llegas aquí y te encuentras eso... Que te van a derribar la casa, que te van a dejar sin terreno, bueno, ¿esto por qué? Esto no es lógico, me van a dejar sin terreno, me van a dejar sin agua, yo creo que es indignación, te indignas. (E.Co.1)

El sentimiento de injusticia está asociado también al carácter impositivo del proyecto por parte del estado, ya que, como afirmó un afectado de Riaño: «no es lo mismo que te quiten, o que te vayas tú voluntariamente y puedas volver el día que quieras» (E.Ri.4). En estos proyectos, se hace evidente la falta absoluta de diálogo y de inclusión de las poblaciones afectadas en las decisiones, y eso aumenta aún más el agravio percibido por los ciudadanos. De hecho, en los tres casos, hemos podido comprobar que la propia planificación se caracteriza todavía por su verticalidad y unilateralidad, de modo que es el estado la única autoridad capaz de determinar el interés general, y eso provoca la oposición de las personas que resisten para defender su vida, su casa o su territorio, tal como expresa esta mujer mexicana:

[...] eso es lo que decían ellos cuando nosotros andamos alegando eso de la presa, eso nos decían, que todo es del gobierno [...] y yo le dije: «Pues, tendrán el derecho, pero aquí no entran en mi casa, si yo no quiero, no entran, aunque sea gobierno». (E.Sg.5)

El sentimiento de injusticia también es alimentado, y a su vez alimenta, la identidad antagónica entre «los de abajo» y «los de arriba», entre los ciudadanos y los políticos que no sólo te quitan tu casa, sino que también se enriquecen y, como se puede leer en el testimonio sucesivo, este comportamiento determina el momento de ruptura, resumido en la pregunta « ¿hasta dónde?»:

[...] además que parecía que era una tomadura de pelo..., de que «te lo quito porque quiero, y me voy a hacer más rico todavía»... Entonces, dices tú: "¿hasta dónde?». (E.Co.10)

El sentimiento de injusticia no sólo está relacionado con la magnitud de la afectación, sino también con la manera cómo esa es perpetrada. En los tres casos estudiados, los entrevistados se quejan de la actitud del gobierno, actitud que alimentó el sentimiento de injusticia y de ultraje, lo cual dio alas a la resistencia, como se puede leer en este extracto: 
[...] la forma..., que lo hicieron en plan «bravo» es peor todavía y por eso fue un poco más eso de la rebelión. (E.Ri.4)

Queremos, además, destacar que, en los casos estudiados, todos los entrevistados coincidían en que, al principio, nadie pensaba que realmente podría vencer al gobierno, pero sentimientos como la rabia, la indignación y la percepción de injusticia les motivó a resistir. Ya lo escribieron Amenta y Polletta (2001: 305), que «generalmente, la gente es motivada por la rabia, la indignación, el miedo, la compasión o el sentimiento de responsabilidad, y no por un optimismo sobre las posibilidades seguras de obtener concesiones políticas a través de la protesta extrainstitucional». En los casos analizados, este elemento es evidente. Las personas lucharon para defender su territorio, porque eso era lo que sentían que tenían que hacer o, como expresó una mujer mexicana: «Es algo que se siente» (E.Sg.2), independientemente de las posibilidades de éxito, como confirma este testimonio:

[...] decidimos subir a los tejados y luchar, sabiendo..., porque ya teníamos conciencia de que aquello era una batalla perdida, pero no podíamos evitar que saliera de dentro lo que eras como persona, un coraje, una rabia, una rebeldía contra la injusticia tan brutal que era aquello. (E.Ri.1)

De esta manera, estas resistencias se transforman así en luchas, no solo por defender el territorio, sino también por salvaguardar la dignidad de sus habitantes, que resisten para no ser estigmatizados como los que no reaccionaron frente al abuso o los que se agacharon frente a los poderosos sin ejercer su derecho de protestar. En el caso de Coín, así lo expresó un entrevistado:

[...] y decimos: «Bueno, vamos a intentarlo, por lo menos», que ver venir las máquinas y hacer un pasillo para que puedan pasar libremente, ¡no!... Todo lo contrario, hay que luchar. Por lo menos, el derecho a la protesta que lo tengamos, que no digan: «Es que no os opusisteis al proyecto». (E.Co.2)

El sentimiento de injusticia que los protagonistas de estos conflictos sienten eleva la lucha a una dimensión de valores, donde lo que está en juego no es conmensurable, es imposible valuarlo económicamente, y por eso no se puede baratear con indemnizaciones ni compromisos. La única salida es el enfrentamiento con los promotores de las obras, un enfrentamiento entre quien posee el poder y la fuerza física y los ciudadanos que reivindican su derecho a existir y decidir sobre sus vidas, como confirma el testimonio de esta mujer mexicana:

Hay cosas que no se hacen tanto por dinero... Si vamos a lo económico, yo no tengo tierra más que la que traigo ahora entre las uñas, y sin embargo lo haces como para defender la dignidad de que no más, porque yo soy fuerte y puedo más que tú, puedo llegar y hacer lo que quiero contigo... Hay cosas que no se justifican nada más por el hecho de poder más que tú. (E.Sg.2) 
Eso permite entender por qué el sentimiento de injusticia influye en la legitimación de la lucha, aun cuando no se piense que se pueda conseguir el objetivo para lo que estés luchando, que también fue fuente de consuelo hasta en Riaño, donde los pueblos fueron inundados, como se puede leer en estas palabras:

[...] por lo menos, lo intentábamos. Queríamos intentarlo y que no nos quedara el remordimiento de no haber luchado por ello... Tengo la conciencia muy tranquila, porque hice lo que pude y si no se salvó desgraciadamente fue porque no pudimos salvarlo, pero intentar lo intentamos, y te queda por lo menos esta satisfacción de haber luchado por ello. (E.Ri.2)

Por último, hay que evidenciar que el sentimiento de injusticia, además de depender de las consecuencias radicales que estas obras presuponen para la gente que vive en los territorios afectados, se construye a través de las narraciones y las experiencias de otras personas, es decir, se enmarca la experiencia en un contexto más amplio, en el que muchas otras personas han sufrido los mismos abusos, y para los que también se lucha, como afirma esta mujer mexicana:

[...] ya tantas personas que le han arrebatado su casa, su hogar, que les han pisoteado sus derechos. (E.Sg.6)

La legitimidad a reaccionar frente a una injusticia no es, así, una cuestión del individuo o de la comunidad afectada, sino más bien un desafío colectivo, que crea un vínculo de unión y solidaridad entre todas las personas que sufren alguna injusticia. De esta manera, podemos afirmar que el sentimiento de injusticia, producto de las experiencias previas de los sujetos, directas e indirectas, es alimentado por el discurso oculto presente en la sociedad y que emerge en los conflictos.

Como hemos mostrado en estas páginas, el choque moral que hace que la gente descubra que el mundo no es como lo pensaba y el enmarcar la experiencia vivida como una injusticia son procesos cognitivos en los que intervienen muchas emociones y que llegan a proporcionar fuerza y legitimidad a la lucha. Percibir lo que se está viviendo como una injusticia, sube el nivel de la contienda, y entran en juego cuestiones como la dignidad, la identidad y los valores de los sujetos, que transforman el conflicto en una lucha basada en principios y en sentimientos, más que en intereses, como veremos sucesivamente tratando el apego al lugar.

\section{El apego al lugar}

Revisando la literatura sobre el apego al lugar ${ }^{17}$, una de las definiciones ampliamente aceptada que encontramos fue la de Low y Altman (1992: 165), que

17. Este concepto ha sido desarrollado principalmente por la psicología ambiental y la sociología urbana. Para una revisión en español de la literatura, véase Hidalgo (1998). Para una lectura desde la perspectiva de los conflictos ambientales, véase Vorkinn y Riese (2001) y Devine-Wright (2009, 2011). 
determinan el apego al lugar como «la relación simbólica formada por personas que dan significados afectivos culturalmente compartidos a un espacio particular o porción de terreno que ofrece las bases para la comprensión individual y colectiva de la relación con el medio ambiente». Aun siendo un concepto que necesita de ulteriores elaboraciones teóricas y análisis empíricos (Giuliani, 2004), tenemos material suficiente como para poder identificar el apego al lugar en nuestros casos de estudio y observar cómo influye en la protesta.

Para empezar, hay que destacar que el apego al lugar está compuesto por un componente físico, relacionado con el lugar que llegamos a querer y con el que nos identificamos, y otro social, relacionado con las personas que viven en el lugar. Ese aspecto es importante, porque, como defienden Hidalgo y Hernández (2001), según si el objeto del apego es más social o físico, la interpretación acerca de la amenaza de un proyecto, y como consecuencia la reacción de los afectados, será distinta.

Una vez aclarado que el apego al territorio es el vínculo afectivo que nos relaciona con una zona concreta, entendida como su ambiente físico y su gente, y que es una construcción individual, influenciada por el contexto social en el que vivimos, necesitamos explicar por qué se trata de un concepto clave para comprender las luchas por la defensa del territorio. El apego al territorio es un proceso normalmente inconsciente y emerge en el momento de la ruptura, cuando se produce una disrupción, es decir, cuando la vida cotidiana está amenazada. Como afirma Jasper (1997: 124): «La resistencia no deriva sólo del posible riesgo percibido, sino también del apego al lugar y a las rutinas que se resumen en el concepto de hogar, porque la seguridad depende de estas rutinas, posesiones materiales y miembros familiares». Perder el pueblo significaba perder una manera de vivir, los vínculos afectivos, la seguridad y, en algunos casos también, la fuente de subsistencia de la familia, como expresa ese entrevistado andaluz:

[... río Grande no es solamente [un río]... Es un modo de vida, en cuanto a tener un pedazo de tierra, una huerta. (E.Co.2)

El apego se fundamenta en el amor hacia el espacio físico, fortalecido por recuerdos y sentimientos como la nostalgia y los vínculos entre su gente, pero también en el sentimiento de seguridad que otorga el vivir en un espacio conocido, con gente conocida. Como escribe Hidalgo (1998: 53): el «apego implica un sentimiento de seguridad asociado a su proximidad y contacto, y una pérdida de esa figura produce miedo y angustia", sentimientos muy comunes en los relatos de los entrevistados, y particularmente fuertes en las entrevistas con los afectados de Riaño que experimentaron la pérdida de su tierra:

Es que la tierra, la vivencia y la infancia son cosas muy importantes. Te quitan eso y te quitan una parte de tu vida [...] te quitan los sentimientos, no te quitan tus sentimientos porque los tienes, pero te quitan esa relación con tu sitio, con tu vida, es que en un vacío que te queda allí. (E.Ri.1) 
Todas estas emociones influyen en el conflicto, ya que, como explica claramente Jasper (1997: 123): «los seres humanos actuarán para prevenir cambios en el ambiente que pueden eliminar esta seguridad». De hecho, la literatura científica sobre realojamientos forzosos ha demostrado como «las personas forzadas a abandonar su barrio manifestaban una gran aflicción, tan intensa como el dolor y la pena por la pérdida de un ser querido» (Hidalgo, 1998: 68). El territorio se convierte en algo más que un espacio físico: son las raíces, los recuerdos, las relaciones humanas, la privacidad y la identidad. Para una comprensión profunda de estos conflictos, resulta ser determinante la dimensión emocional, ya que, como afirma esta mujer:

Aquí era más de sentimientos, no era tanto por lo que nos pudieran dar... Pensábamos en todo, pero más que nada, en lo que nosotros ya hemos vivido [...] en otro lugar no eres nadie, eres un ave, que pasa y total... Y aquí, para nuestra gente, aquí sí somos algo... (E.Sg.5)

Y ese vínculo emocional con el lugar es una de las motivaciones para la acción, como expresa este entrevistado de Riaño:

Tenía veintitrés años cuando vinieron a echarme, por lo tanto ese es el motivo. Los niños crecieron y se hicieron mayores, echaron raíces, y muchas raíces [...] esa fue la causa principal de la protesta contra Riaño. (E.Ri.1)

Además del sentimiento de seguridad, al que está relacionado la elaboración de la amenaza, Jasper vincula el apego al territorio también con la dignidad, concebida como «una serenidad y un orgullo que deriva de la confianza en el lugar de uno, si ese lugar es la parte social y el contexto físico de uno» (1997: 126). Como hemos visto en el apartado precedente, identidades estigmatizadas pueden minar la dignidad de un pueblo. Esta estigmatización hace que la defensa del propio territorio se convierta en una cuestión de dignidad, como se puede apreciar en este testimonio:

Ellos nos ponían a nosotros que éramos como unos egoístas [...]. ¿Es que hay ciudadanos de primera y de segunda, o qué pasa aquí? Son cosas que te indignan, y esa era la causa por la cual la gente se levantó. (E.Co.1)

Como confirma este testimonio, una de las grandes acusaciones que se hace a los colectivos y a los ciudadanos que participan en un conflicto ambiental es la de ser egoístas ${ }^{18}$. Pero, del análisis de estas experiencias, emerge que la motivación por la que se lucha en contra de la presa no es porque se encuentra en el propio término municipal, en su "patio trasero", sino porque su construcción significa la aniquilación de las relaciones humanas, las experiencias de vida, los sentimientos y los recuerdos.

18. De nuevo, nos referimos a la etiqueta NIMBY, que resalta la dimensión egoísta de estos conflictos con el objetivo de desacreditarlos. 
Todas estas emociones que construyen el vínculo con el territorio desempeñan un papel muy importante en el proceso cognitivo, y eso contribuye a ver las cosas de manera distinta y a apreciar más lo que se tiene delante. De hecho, una de las consecuencias del conflicto que hemos apreciado fue que las personas se reapropiaron del territorio considerándolo como algo que le pertenece, así como lo cuenta esta mujer:

Yo [he aprendido] a valorar más mi pueblo, quererlo más, y tratar de seguir adelante defendiendo lo que al gobierno no le ha costado nada, ni tampoco ha pisoteado. (E.Sg.5).

Para terminar el vínculo afectivo que se construye con el territorio, resulta ser determinante en la comprensión de los conflictos por la defensa del mismo, ya que se lucha para proteger lo que se ama y lo que se respeta. Pasamos ahora a la segunda parte del análisis, en la que presentaremos algunos resultados de estas experiencias de lucha y cómo las emociones influyen en ellos.

\section{Las emociones como motor de cambio: energía emocional y empoderamiento}

Terminamos el artículo con un último parágrafo en el que describiremos como las emociones pueden influir en el empoderamiento de los individuos que luchan. Es importante comprender que el efecto que pueden producir las emociones depende de la experiencia de los sujetos, ya que emociones asociadas a vivencias positivas y negativas pueden causar respuestas diferentes. Las emociones que se asocian a experiencias negativas, como el miedo causado por la posible inundación del pueblo, por un lado, pueden entristecer y desanimar, pero, por otro, pueden también ser motor de acción, ya que se percibe la pérdida de tal manera que no hay nada más importante que perder. Estas emociones, además, pueden contribuir a comprender la necesidad de la gente de querer «volver a la normalidad» después del conflicto. La necesidad de tranquilidad que hace que muchas personas no quieran implicarse de inmediato en otras contiendas, y que algunos activistas o académicos que aceptan la interpretación NIMBY interpretan como egoísmo, se puede concebir de manera distinta si se considera la intensidad emocional y la dedicación que requiere la lucha, tal como lo expresa esta mujer.

[...] saber que amanece y que tienes una tranquilidad tan bonita que se ha acabado lo de la presa... Es una tranquilidad hermosa. (E.Sg.5)

$\mathrm{Si}$, por un lado, la experiencia de la lucha es intensa, estresante y a menudo extenuante, por otro lado, también es considerada por sus protagonistas como positiva. Para entender el "placer de la lucha» (Jasper, 1997), consideramos que sea útil el concepto de energía emocional, que Jasper (2011: 294) define como «la energía que se difunde desde cada interacción y que transforma las emociones reflexivas en estados de ánimo, en vínculos afectivos y, finalmente, 
en emociones morales». Esa energía emerge en muchas de las narraciones de las personas entrevistadas:

[...] entonces sientes una satisfacción cuando ve que toda la gente responde, que toda la gente está unida, que aunque pasan cosas, cuando ve que toda la gente está motivada, dispuesta a defender sus derechos, yo creo que es la mayor satisfacción... Que veas que, aunque te quieran aplastar..., esa actitud de la gente tan positiva, que no tan fácilmente se doblega ni se deja. (E.Sg.6)

Esa energía, que emerge en los momentos colectivos y en los rituales, contribuye a promover el cambio animando a los sujetos, como un carburante para la acción colectiva. De ahí la importancia de los momentos colectivos en la protesta, de la música y los bailes que a menudo acompañan a estas experiencias, a las manifestaciones públicas y a las pequeñas conquistas, ya que «cada victoria, aunque pequeña, produce confianza, atención y energía emocional, aspectos que serán una ventaja para futuras acciones» (Jasper, 2011: 296), así como lo expresa esa mujer:

[...] es que fue un subidón cuando se paró la historia, como si nos hubiese tocado la lotería, eso fue un subidón general para todo el mundo... Y fue el resultado de toda la lucha, de todo el esfuerzo de un montón de gente. (E.Co.3)

Esa energía influye en el empoderamiento de las personas implicadas en el conflicto y se manifiesta en cambios, tanto a nivel individual como colectivo, en la esfera personal (se habla de empoderamiento psicológico), como en la política (empoderamiento político) (Friedmann, 1998). El empoderamiento, que definimos como «una condición sociopsicológica de confianza en las habilidades de uno que desafía las relaciones existentes de dominación» (Drury y Reicher, 2005: 35), es uno de los resultados de las luchas ambientales (Drury y Reicher, 1999, 2000 y 2005; Lake, 1993; Krauss, 1989), que lleva a un cambio social y que depende de las emociones experimentadas en la protesta. Uno de los cambios observados en relación con el empoderamiento es la pérdida del miedo hacia la autoridad, como comenta este hombre:

Yo siento que desde entonces no le tengo miedo ni al gobierno, ni a nadie... Son humanos también, y también tienen miedo igual que la gente. (E.Sg.4)

La pérdida del miedo se hace evidente durante el conflicto, en los enfrentamientos, y se contagia entre los protagonistas, con lo cual se crean fuertes vínculos entre las personas. En los casos de Coín y San Gaspar, el empoderamiento se manifiesta en la toma de conciencia de que el gobierno no es todopoderoso y del poder que tienen los ciudadanos:

[...] eso a mí me ha servido mucho, y también saber que juntos se pueden conseguir un montón de cosas. Hasta los colectivos minoristas pueden conse- 
guir un montón de cosas si se lo proponen y si tienen la verdad por delante y la respaldan. (E.Co.7)

En el caso de Riaño, hemos podido observar que, durante la resistencia, surgieron experiencias de autoorganización, ya que los jóvenes que vivían en Riaño antes de los desalojos se empeñaron en mantener el pueblo que se estaba dejando morir, como cuentan estos entrevistados:

[...] él se presentó como alcalde del Ayuntamiento, y yo me presenté como presidente de la junta vecinal, y ganamos por mayoría absoluta, y nos dimos cuenta de que el pueblo estaba con nosotros. (E.Ri.2)

Finalmente, el empoderamiento, es decir, el «poder de» cambiar las cosas (Dallago, 2006), está fortalecido por el éxito del conflicto en los casos de Coín y San Gaspar, mientras que, en el caso de Riaño, se experimenta durante la resistencia, pero no en relación con el resultado, ya que, finalmente, perdieron su lucha. Aun así, en todos los casos, las personas entrevistadas reconocen la legitimidad de la lucha, no sólo para conseguir sus objetivos, sino también para defender su dignidad, como hemos dicho al hablar del sentimiento de injusticia, y como leemos en este extracto:

[...] hay que luchar en lo que se cree aunque la batalla esté perdida de antemano [...] había que seguir, tampoco se lo vas a poner fácil. (E.Ri.3)

Las personas empoderadas no sólo consideran la lucha como una vía legítima para defenderse y actuar contra las injusticias, sino que también reconocen la importancia de la unión para conseguir sus objetivos: "He visto que, cuando el pueblo se une, ni política ni nada» (E.Co.7).

La unión influye positivamente en la experiencia, porque anima a seguir luchando:

[...] cuando el grupo es fuerte, ya puedes tú gritar, puedes decirles sus verdades y no hay problemas..., pero a un principio no te animas... (E.Sg.7)

El empoderamiento se manifiesta también en la conciencia de la responsabilidad de los ciudadanos, que, por ejemplo, en el caso de Riaño, se manifestó en la toma de los ayuntamientos de la comarca por parte de jóvenes antipresa poco antes de los derribos, y en otras ocasiones con la conciencia de que los mejores representantes de los ciudadanos son ellos mismos, aunque no tengan experiencia:

[...] hubo otras ocasiones en que querían que nos representaran personas más preparadas, que sabían hablar [...] yo creo que tiene más valor la ponencia de una persona que está viviendo el problema que alguien que va a hablar muy bonito y exponer [...] creo que cuenta más el dicho de la persona afectada..., aunque no lo puedan entender muy bien. (E.Sg.7) 
El empoderamiento es el resultado de la unión de la gente y una consecuencia del abandono por parte de las autoridades de sus responsabilidades, ya que las personas, conscientes de que nadie les podrá resolver sus problemas, deciden organizarse y luchar en contra del proyecto, y eso produce el proceso de empoderamiento:

[...] fue cuando nosotros sentimos que ante nadie, o sea ante nadie tenía valor lo que nosotros estábamos defendiendo. Era una lucha de la comunidad nada más, sin ninguna autoridad, sin ningún partido político y sin ningún apoyo, ni religioso, ni de ningún lado. Era rifárnosla nosotros solos, y así nos aventamos, se unió la comunidad, y salimos adelante. (E.Sg.9)

Por último, recordamos que el empoderamiento se puede observar en distintas dimensiones, desde la individual hasta la política. Respecto a la dimensión individual, los sujetos expresan que consiguieron superar prejuicios que tenían, por ejemplo, hacia quienes luchaban o hacia colectivos ecologistas, así como a tener mayor confianza en sí mismos:

[...] fue como un momento que me hizo revalorarme, o sea descubrir quizás capacidades que no había desarrollado, o sea como que me revaloré a mí mismo [...] No me imaginaba el cambio que iba a traer esto en mí realmente [...] descubrí que yo podía también, podía tener la capacidad de hablar [...] fueron momentos que sí despertaron en mí otro tipo de persona que no era yo. (E.Sg.1)

La elección de trabajar con personas «comunes y corrientes» nos ha permitido observar el empoderamiento muy claramente, ya que, como afirman sobre todo los entrevistados de Riaño y San Gaspar, tuvieron que partir desde cero, ya que no tenían ninguna experiencia previa, como se puede apreciar en este testimonio:

[...] éramos gente que no teníamos mucha idea de nada... Hacía poco que había llegado la democracia y nosotros no sabíamos..., y luchamos con lo que podíamos, subiendo al tejado. (E.Ri.5)

Por último, queremos destacar que el empoderamiento está relacionado con las emociones asociadas a experiencias positivas y con la energía emocional que caracterizan la experiencia, desde la satisfacción de que es posible cambiar las cosas, consecuencia del éxito del conflicto, como en los casos de Coín y San Gaspar:

[...] al final, con lo que te quedas es con eso: jes posible! Si te lo curras, y crees en la historia, y tienes esperanza, y defiendes realmente porque crees en la historia, es posible que se pueda cambiar algo... Yo me quedo con eso. (E.Co.3) 
Pero también tiene que ver con el consuelo de haber hecho todo lo posible para salvar el pueblo. Es el caso de Riaño, donde ese sentimiento, unido a la injusticia sufrida, hace que ahora, después de más de 25 años, algunos de ellos sigan intentando recuperar el valle, a fin de poder «justiciar un poquito tanta indignación» (E.Ri.1). Y con ese último testimonio, concluíamos nuestro análisis sobre la dimensión emocional de los conflictos ambientales, para presentar unas primeras conclusiones de nuestro estudio.

\section{Conclusiones}

En este trabajo, hemos presentado los resultados de investigación relativos al estudio de tres luchas por la defensa del territorio analizadas desde abajo, es decir, desde la perspectiva de los que lucharon, centrándonos en su experiencia y sus emociones. El análisis de la dimensión sentimental de estas experiencias nos ha permitido mostrar como las emociones influyen tanto en la motivación para la acción, como en el proceso de empoderamiento, considerado como una de las consecuencias de estas resistencias.

Después de lo que hemos presentado en estas páginas, creemos que es evidente que estas luchas no se limitan a "defender su patio trasero», de manera, egoísta y provinciana, sino el territorio que se ama, el estilo de vida imperante, las relaciones sociales y la dignidad y la identidad de las personas que habitan estas zonas. Hemos mostrado que lo que se esconde detrás de las resistencias por la defensa del territorio implica emociones, vínculos afectivos, el derecho de poder decidir dónde y cómo vivir sin que alguien, desde fuera o desde lo alto, te pueda privar de ello. Los procesos cognitivo-emocionales que los actores experimentan permiten que valores subyacentes vuelvan a la superficie en un proceso de reautoaprendizaje que, en palabras de Paco Puche, activista de la Nueva Cultura del Agua en Andalucía:

[...] es un aprendizaje que no es un aprendizaje de cosas nuevas, sino de cosas que ya existían y de pronto se han rememorado. Es un aprendizaje de dentro a fuera. Muy potente, por tanto, inolvidable. (E.Ex.1)

El análisis de procesos cognitivos como el choque moral y el sentimiento de injusticia permiten comprender las respuestas de las comunidades locales contra los proyectos que los amenazan. Si las emociones desempeñan un papel importante en la lucha, el apego al lugar en estos casos proporciona las razones sentimentales casi nunca consideradas en los análisis, aunque sea ampliamente demostrado que el ser humano actúa movido por emociones. Finalmente, las emociones influyen en el cambio de las personas, fortaleciéndolas, empoderándolas, haciéndoles sentir que «sí se puede» y facilitando la emersión o difusión de nuevos valores que hace de estas luchas, independientemente de sus resultados, experiencias emancipatorias, ya que, como afirmó Holloway (2009: 17): «en el proceso de decir “¡no!", [las personas] desarrollan formas de autodeterminación o articulan conceptos alternativos de cómo debería ser el mundo». 


\section{Referencias bibliográficas}

AA. VV. (2009). América Latina: Riqueza privada, pobreza pública. Quito: CIDSE y ALAI.

Amenta, Edwin y Polletta, Francesca (2001). «Second the Emotion?: Lessons from Once-novel Concepts in Social Movement Research». En: Goodwin, Jeff; Jasper, James M. y Polletta, Francesca. Passionate Politics: Emotions in Social Movements. Chicago: University of Chicago Press, 303-316.

AtKInson, Robert (2002). L'intervista narrativa: Raccontare la storia di sé nella ricerca formativa, organizzativa e sociale. Milán: Raffaello Cortina Editore.

Dallago, Lorenza (2006). Che cos'é l'empowerment. Roma: Carocci Editore.

Della Porta, Donatella (2008). «Eventful Protest, Global Conflicts». Distinktion: Scandinavian Journal of Social Theory [en línea], 17, 27-56. <http://dx.doi.org/10.1080/1600910X.2008.9672963>.

- (2010). L'intervista qualitativa. Bari: Laterza.

Delgado Ramos, Gian Carlo (coord.) (2013). Ecología política del extractivismo en América Latina: Casos de resistencia y justicia socioambiental. Buenos Aires: CLACSO.

Devine-Wright, Patrick (2009). «Rethinking Nimbyism: The Role of Place Attachment and Place Identity in Explaining Place-Protective Action». Journal of Community \& Applied Social Psychology [en línea], 19, 426-441. $<$ http://dx.doi.org/10.1002/casp.1004>.

- (2011). "Place attachment and public acceptance of renewable energy: A tidal energy». Journal of Environmental Psychology [en línea], 31, 336-343. <http://dx.doi.org/10.1016/j.jenvp.2011.07.001>.

Diana, Paolo y Montesperelli, Paolo (2005). Analizzare le interviste ermeneutiche. Roma: Carocci.

Drury, John y Reicher, Steve (1999). "The Intergroup Dynamics of Collective Empowerment: Substantiating the Social Identity Model of Crowd Behavior». Group Processes Intergroup Relations [en línea], 2, 381-402. <http://dx.doi.org/10.1177/1368430299024005>.

- (2000). "Collective Action and Psychological Change: The Emergence of New Social Identities». The British Journal of Social Psychology [en línea], 39, 579-604. <http://dx.doi.org/10.1348/014466600164642>. PMid:11190686.

- (2005). «Explaining Enduring Empowerment: A Comparative Study of Collective Action and Psychological Outcomes». European Journal of Social Psychology [en línea], 35, 35-58. <http://dx.doi.org/10.1002/ejsp.231>.

Fedi, Angela y Mannarini, Terri (eds.) (2008). Oltre il nimby: La dimensione psicosociale della protesta contro le opere sgradite [en línea]. Milán: Franco Angeli. <http://dx.doi.org/10.1016/j.nimb.2008.03.064> <http://dx.doi.org/10.1016/j.nimb.2008.03.003>.

Flam, Helena y King, Debra (2005). Emotions and Social Movements. Oxon: Routledge.

Flick, Uwe (2000). «Episodic Interviewing». En: Bauer, Martin y Gaskell, George (eds.). Qualitative Researching with Text, Image and Sound: A Practical Handbook. Londres: Sage, 75-92.

- (2004). Introducción a la investigación cualitativa. Madrid y A Coruña: Morada y Fundación Paideia Galiza.

Friedmann, John (1998). Empowerment: the Politics of Alternative Development. Cambridge, Massachusetts: Blackwell. 
Gamson, William A. (1992). Talking Politics. Cambridge: University Press. PMid:1410280.

Gibson, Timothy A. (2005). «Nimby and the Civic Good». American Sociological Association, 4 (4), 381-401.

Giuliani, Maria Vittoria (2004). «Teoria dell'attaccamento ai luoghi». En: Bonnes, Mirilia; Bonaiuto, Marino y Lee, Terence (eds.). Teorie in pratica per la psicologia ambientale. Milán: Raffaello Cortina Editore.

Gould, Deborah B. (2004). «Passionate Political Processes: Bringing Emotions Back into the Study of Social Movements». En: Goodwin, Jeff y JAsper, James M. (eds.). Rethinking Social Movements: Structure, Meaning and Emotion. Lanham: Rowman \& Littlefield, 155-175.

Hidalgo Villodres, M. a Carmen (1998). Apego al lugar: Ámbitos, dimensiones y estilos. San Cristóbal de La Laguna, Santa Cruz de Tenerife: Universidad de La Laguna. Tesis doctoral.

Hidalgo Villodres, Ma Carmen y Hernández, Bernardo (2001). «Place Attachment: Conceptual and Empirical Questions». Journal of Environmental Psychology [en línea], 21, 273-281. <http://dx.doi.org/10.1006/jevp.2001.0221>.

Holloway, John (2009). "Teoría Volcánica». En: Holloway, John; Matamoros, Fernando y Tischler, Sergio. Pensar a Contrapelo: Movimientos sociales y reflexión crítica. México: Bajo Tierra Ediciones y Sísifo Ediciones.

- (2011). Agrietar el capitalismo: El hacer contra el trabajo. Buenos Aires: Herramienta.

Holloway, John; Matamoros, Fernando y Tischler, Sergio (2009). Pensar a Contrapelo: Movimientos sociales y reflexión crítica. México: Bajo Tierra Ediciones y Sísifo Ediciones.

Jasper, James M. (1997). The Art of Moral Protest: Culture, Biography, and Creativity in Social Movements [en línea]. Chicago: University of Chicago Press. <http://dx.doi.org/10.7208/chicago/9780226394961.001.0001>.

- (1998). «The Emotions of Protest: Affective and Reactive Emotions in and Around Social Movements». Sociological Forum [en línea], 13, 397-424. <http://dx.doi.org/10.1023/A:1022175308081>.

- (2011). «Emotion and Social Movements: Twenty Years of Theory and Research». Annual Review of Sociology [en línea], 37, 285-303. <http://dx.doi.org/10.1146/annurev-soc-081309-150015>.

- (2012). «¿De la estructura a la acción?: La teoría de los movimientos sociales después de los grandes paradigmas». Sociológica, 75, 7-48.

Krauss, Celene (1989). "Community Struggles and the Shaping of Democratic Consciousness». Sociological Forum [en línea], 4 (2), 227-238. <http://dx.doi.org/10.1007/BF01112422>.

- (1993). «Women and Toxic Waste Protests: Race, Class and Gender as Resources of Resistance». Qualitative Sociology [en línea], 16 (3), 247-262. <http://dx.doi.org/10.1007/BF00990101>.

LAKE, Robert W. (1993). «Planners' Alchemy Transforming NIMBY to YIMBY: Rethinking NIMBY». Journal of the American Planning Association [en línea], 59 (1), 87-93. <http://dx.doi.org/10.1080/01944369308975847>.

Low, Setha M. y Altman, Irwin (1992). Place Attachment [en línea]. Nueva York: Plenum. <http://dx.doi.org/10.1007/978-1-4684-8753-4>. 
Poma, Alice (2013). Conflictos ambientales y cambio cultural: Un análisis desde la perspectiva de los afectados. Sevilla: Universidad Pablo de Olavide. Tesis doctoral.

Poma, Alice y Gravante, Tommaso (2013) . "Emociones, protesta y cambio social: Una propuesta de análisis». Revista Latinoamericana de Estudios sobre Cuerpos, Emociones y Sociedad (Relaces), 13 (5), 21-34.

Regalado, Jorge (2012). "Notas deshilvanadas sobre otra epistemología». En: AA. VV. Hacer politica para un porvenir más allá del capitalismo. Guadalajara, México: Las Grietas Editores.

Sanz Hernández, María Alexia (2000). Ojos Negros: La memoria de un pueblo. Teruel: Instituto de Estudios Turolenses y Ayuntamiento de Ojos Negros.

Scotт, James C. (2000). Los dominados y el arte de la resistencia. México: Era.

Vorkinn, Maritt y Riese, Hanne (2001). «Environmental Concern in a Local Context: The Significance of Place Attachment». Environment and Behavior [en línea], 33, 249-263. <http://dx.doi.org/10.1177/00139160121972972>.

Uribe-Salazar Gil, Clara de y Martí, Pascual (2013). "Los NIMBYs como generadores de situaciones de crisis». Más Poder Local, 18, 6-13.

Wolsink, Maarten (2006). "Invalid Theory Impedes our Understanding: A Critique on the Persistence of the Language of NIMBY». Transactions of the Institute of British Geographers [en línea], 31 (1), 85-91. <http://dx.doi.org/10.1111/j.1475-5661.2006.00191.x>.

Tabla de las entrevistas citadas

\begin{tabular}{ccll}
\hline Etiqueta & Género $(\mathrm{H} / \mathrm{M})$ & \multicolumn{1}{c}{ Caso estudiado } & \multicolumn{1}{c}{ Fecha } \\
\hline E.Ri.1 & $\mathrm{H}$ & Riaño, España & Agosto de 2010 \\
E.Ri.2 & $\mathrm{H}$ & Riaño, España & Agosto de 2010 \\
E.Ri.3 & $\mathrm{H}$ & Riaño, España & Agosto de 2010 \\
E.Ri.4 & $\mathrm{H}$ & Riaño, España & Mayo de 2011 \\
E.Ri.5 & $\mathrm{M}$ & Riaño, España & Mayo de 2011 \\
E.Sg.1 & $\mathrm{H}$ & San Gaspar, México & Noviembre de 2010 \\
E.Sg.2 & $\mathrm{H}$ & San Gaspar, México & Noviembre de 2010 \\
E.Sg.4 & $\mathrm{H}$ & San Gaspar, México & Noviembre de 2010 \\
E.Sg.5 & $\mathrm{M}$ & San Gaspar, México & Noviembre de 2010 \\
E.Sg.6 & $\mathrm{M}$ & San Gaspar, México & Enero de 2011 \\
E.Sg.7 & $\mathrm{H}$ & Teocaltiche, México & Enero de 2011 \\
E.Sg.9 & $\mathrm{M}$ & San Gaspar, México & Enero de 2011 \\
E.Co.1 & $\mathrm{H}$ & Coín, España & Marzo de 2010 \\
E.Co.2 & $\mathrm{H}$ & Coín, España & Marzo de 2010 \\
E.Co.3 & $\mathrm{M}$ & Coín, España & Mayo de 2011 \\
E.Co.5 & $\mathrm{M}$ & Coín, España & Mayo de 2010 \\
E.Co.7 & $\mathrm{H}$ & Coín, España & Mayo de 2010 \\
E.Co.10 & $\mathrm{M}$ & Coín, España & Mayo de 2011 \\
\hline
\end{tabular}

